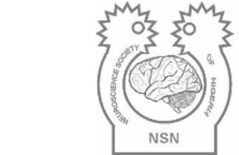

Official Journal of the Neuroscience Society of Nigeria (NSN)

\title{
Sulphoraphane Supplementation Ameliorates Behavioural Impairments and Hippocampal Neurodegeneration Induced by Lead Exposure in Adult Wistar Rats
}

\author{
Babatunde Ogunlade ${ }^{1,2}$, Olasumbo O. Afolayan ${ }^{2}$ and Sunday A. Adelakun ${ }^{1}$ \\ ${ }^{1}$ Department of Human Anatomy, Federal University of Technology, Akure, Nigeria; ${ }^{2}$ Department of Anatomy, College of \\ Medicine, University of Lagos, Lagos, Nigeria
}

Received:

July 2020

Accepted:

September 2020

\begin{abstract}
Lead $(\mathrm{Pb})$ exposure induces oxidative stress causing imbalance in antioxidant enzymes, cognitive impairments and neurodegeneration. This study investigated the neuroprotective and antioxidant properties of sulphoraphane (SFN) on Pb-induced neurotoxicity of adult Wistar rats. Forty animals (150 $\pm 20 \mathrm{~g}$ ) were divided into four groups $(n=10)$ : Group A received normal saline as placebo; Group $B$ received $50 \mathrm{mg} / \mathrm{kg}$ body weight (bw) of Lead only; Group C received a combination of $50 \mathrm{mg} / \mathrm{kg}$ bw of Lead and $50 \mathrm{mg} / \mathrm{kg}$ bw of SFN; Group D received $50 \mathrm{mg} / \mathrm{kg}$ bw of SFN only. All administration was through oral gavages for 28 days; animals underwent behavioural tests (Morris water and Y- mazes); and thereafter sacrificed and brains extracted. Biochemical estimations of antioxidants (superoxide dismutase, reduced glutathione, and catalase), oxidative stress markers (malondialdehyde, nitric oxide, and hydrogen peroxide), neurotransmitters (dopamine, serotonin, and norepinephrine) and hippocampal histology were done. The results showed significant increase in escape latency, norepinephrine and oxidative stress markers with concomitant decrease percentage correct alternation, serotonin, dopamine and antioxidant enzymes in $\mathrm{Pb}$ exposed rats compared with the control. However, the co-administration of $\mathrm{SFN}$ and $\mathrm{Pb}$ significantly attenuated $\mathrm{Pb}$ neurotoxicity. Sulphoraphane is capable of ameliorating oxidative stress induced neurobehavioural deficits and hippocampal neurochemistry caused by $\mathrm{Pb}$ exposure in Alzheimer's type animal model of neurodegenerative disorder.
\end{abstract}

Key words: Lead; Hippocampal neurodegeneration; Sulphoraphane; Behavioural stress test; Oxidative stress

\section{INTRODUCTION}

Neurotoxicity is one of the leading causes of neurodegenerative disorders with several complications such as cognitive impairment, disorders in memory (long and short term), mood swings and onset of psychiatric disturbances (CabanHolt et al. 2005; Han et al. 2011; Mason et al. 2013). Alzheimer's disease (AD) is widely known for its prevalence, progression and fatality. It is usually associated with aging and it manifests clinically with symptoms including (but not restricted to) memory impairment and difficulty in the performance of normal daily activities (Bakulski et al. 2012). Within the last 50 years, $A D$ has gone from a state of obscurity (although relative) to becoming a defining characteristic of a normal, industrialized society (Bertram et al. 2009). Research has provided evidence of an association between $A D$ and overexposure to environmental neurotoxicants (Hardy 1997). Neurotoxicants could exist in the form of elements such as aluminium, zinc, nickel, lead, cadmium, manganese and cadmium (Shcherbatykh

Correspondence: Babatunde Ogunlade, PhD, Department of Human Anatomy, Federal University of Technology, Akure, Nigeria. Email: bogunlade@futa.edu.ng; Phone: $+2348036318757$ 
and Carpenter 2007; Frisardi et al. 2010).

Lead is a soft, malleable, and extremely toxic heavy metal that occurs naturally in the earth's crust (Mason et al. 2013). It is found in all parts of the environment, derived majorly from human activities such as manufacturing, mining and burning fossil fuels (Sanders et al. 2009). It is utilized in a variety of products such as gasoline, paints, ceramics, ammunition, water pipes, solders, cosmetics, hair dye, farm equipment, airplanes, shielding for $\mathrm{x}$-ray machines, manufacture of corrosion and acid resistant materials used in the building industry (ATSDR 2006).

Chronic $\mathrm{Pb}$ exposure has been associated with the incidence of neurodegenerative disorders such as Alzheimer's and Parkinson's diseases (MonnetTschudi et al. 2006). AD is characterized by the formation of waxy plaques consisting predominantly of $\beta$-amyloid protein between neurons (a known neuropathological hallmark of the disease), and $\mathrm{Pb}$ has been known to increase the expression of the amyloid precursor protein (APP) which precedes the formation of these plaques (Monnet-Tschudi et al. 2006).

Exposure to lead cause severe genetic, blood and mitochondria destructions (Anderson et al. 1996), resulting in several abnormalities such as; early onset of apoptosis, excitotoxicity affecting storage of neurotransmitters, release and modification of neurotransmitter receptors, mitochondria damage, cerebrovascular endothelial cells damage, astroglia and oligodendroglia destructions (Sharma et al. 2015). There is also indubitable evidence that increased exposure to lead acetate results in adverse effects on the central nervous system (CNS) and exposures in early developmental stages can result in neurodegeneration later in life (Bellinger et al. 2011).

Sulphoraphane (SFN) is a phytochemical compound; its precursor glucoraphanin is found in cruciferous vegetables, with concentrations in broccoli sprouts being the highest (Shiina et al. 2015). SFN belongs to a group of plant-derived compounds called isothiocyanates. It is a powerful inducer of the nuclear factor erythroid-related factor 2 (Nrf2) antioxidant response element (ARE) pathway which plays a major role in up-regulating cellular defences to prevent against oxidative stress (Trio et al. 2016). Several intense and in-depth researches have been carried out with the purpose of investigating the ability of SFN to decrease the risk of various cancers and reduce the damage associated with the various forms of oxidative stress (Kim et al. 2017). SFN has very strong antioxidant and anti-inflammatory properties which enable it to drastically reduce cytotoxicity in the CNS (Shapiro et al. 2006). Animal studies have suggested that SFN supplementation can modify many debilitating CNS diseases including Parkinson's disease, epilepsy and stroke among others (Shapiro et al. 2006). This study therefore attempts to provide an insight into SFN supplementation response on neurobehavioural stress test and Alzheimer's-type neurodegeneration subjected to chronic $\mathrm{Pb}$ exposure in adult Wistar rat.

\section{MATERIALS AND METHODS}

\section{Chemicals}

Lead acetate $\left(\left[\mathrm{C}_{2} \mathrm{H}_{3} \mathrm{O}_{2}\right]_{2} \mathrm{~Pb} .3 \mathrm{H}_{2} \mathrm{O}\right)$ was obtained from Sigma Chemical Corporation (USA) and SFN was procured from Toronto Research Chemicals Inc. (Canada). All other chemicals used in the study were of analytical grade.

\section{Ethics Approval}

The experimental procedures were conducted in accordance with the National Institute of Health of the United States of America guidelines for the care and use of laboratory animals in line with guidelines of the Department of Human Anatomy, Federal University of Technology, Akure and the Health Research and Ethical Committee of the University of Lagos and Federal University of Technology, Akure (HREC/19/0120).

\section{Animals and Experimental Design}

Forty adult male Wistar rats weighing between $130 \mathrm{~g}$ and $170 \mathrm{~g}$ were obtained from the breeding colony of the Faculty of Agriculture and Agricultural Technology, Federal University of Technology, Akure, Nigeria. The rats were housed in the laboratory animal house, Department of Human Anatomy, Federal University of Technology, Akure, Ondo State, Nigeria. The rats were acclimatized for 7 days; maintained under standard laboratory conditions (12- hour light/dark cycles) and had free access to a commercial pellet diet and water ad libitum. The animals were maintained under a controlled room temperature of $25 \pm 2{ }^{\circ} \mathrm{C}$ and relative humidity of $60 \pm 5 \mathrm{gm}^{-3}$. The floor of the cage was lined with carpet pieces and sprayed with coarse saw dust which served as a cushion. The coarse saw dust was changed every day to dispose waste droppings and maintain proper hygiene. The use of the experimental animals was in accordance to the Guide for the Care and Use of Laboratory Animals and approved by the Health Research Ethics Committee of the Federal University of Technology, Akure, Ondo state, Nigeria. (HREC/19/0120).

\section{Experimental Design}

The animals were divided into four groups $(n=10)$. Lead acetate $(\mathrm{Pb})$ dosage (Owoeye and Ojora 2015) and SFN dosage (Zhou et al. 2016) were dissolved in distilled water and prepared freshly each day for administration. The groups were as follows.

Group A (control) received normal saline solution (sodium chloride) orally as placebo; Group B 
received $50 \mathrm{mg} / \mathrm{kg}$ body weight (bw) of lead acetate only orally; Group C received $50 \mathrm{mg} / \mathrm{kg}$ bw of SFN simultaneously with $50 \mathrm{mg} / \mathrm{kg}$ bw of lead acetate orally; Group D received $50 \mathrm{mg} / \mathrm{kg}$ bw of SFN only orally

All the groups were treated under the same housing conditions for 28 days. The animals were weighed and behavioural observations were recorded. The animals underwent behavioural studies after the last administration. At the end of the experiment, animals were sacrificed through cervical dislocation. The organs were excised, cleaned and washed with saline $(0.9 \%$ sodium chloride)

\section{Behavioural Parameters}

Prior to the commencement of the experiment, the rats underwent neurobehavioural training using Morris water maze (MWM) and $Y$ maze tests for spatial memory and working memory (Vorhees and Williams 2006; Kim et al. 2013)

\section{Morris Water Maze Test}

This test was carried out to assess the spatial learning and memory of the rats. A pool of water measuring $100 \mathrm{~cm}$ in diameter and $30 \mathrm{~cm}$ in depth was used. An escape platform, $2.5 \mathrm{~cm}$ deep from the surface of the water, was placed in one of the quadrants outside of which was a visual cue. The animals were trained at day 0 before the commencement of the treatment. During the training, each rat was placed in each of the other three quadrants for a maximum period of $60 \mathrm{sec}$ to find the escape platform at intervals of $25 \mathrm{~min}$ between quadrants until the escape latency reduced to less than $25 \mathrm{sec}$. During the test (after completion of the last administration), the pool was coloured and the animals were placed in each of the three quadrants different from the escape platform quadrant at an interval of 25 min between quadrants. The time taken to find the escape platform was recorded as the escape latency.

\section{Y-maze Test}

The rats underwent neurobehavioural training at day 0 after acclimatization period before the commencement of the experiment and behavioural testing at the end of the last administration. The $Y$ maze was carried out in a quiet dimly lit room between the hours of 9 am and $3 \mathrm{pm}$. All behavioural tests were videotaped and later scored by an independent observer who was unaware of the experimental protocol. All apparatus used for the tests were cleaned with $10 \%$ ethanol to remove possible bias due to odour left by the previous animal. This test was used to examine the working and cognitive memory of the rats. The animals were placed in a Y-maze whose arms measured $75 \mathrm{~cm}$ in length and $15 \mathrm{~cm}$ in breadth with an angle of $120^{\circ}$ between the arms. The rats are placed on a predetermined start arm and were allowed to explore the maze for $5 \mathrm{~min}$. Arm entry (hind limbs completely in the arm) was scored. A correct alternation was scored when the animal successfully explored each of the three arms of the maze per triad of exploration (i.e. entering all 3 arms in the overlapping triplet sets are defined as correct alternation) (e.g., $X Y Z, Z X Y$, or $Y Z X)$. Once two arms were explored per triad of exploration (e.g., $X Y X, Z X Z, Y X Y$ ), it was considered an incorrect alternation. The percentage of spontaneous alternation was calculated as: [correct alternation/ (total number of arm entries - 2)] × 100 .

\section{Tissue Collection and Processing}

After the behavioural tests were concluded, the rats were subjected to cervical dislocation, and the brain tissues were immediately excised and dissected into two hemispheres. All the right hemispheres were fixed in $4 \%$ paraformaldehyde for histological processing, while the left hemispheres were rinsed three times in $0.25 \mathrm{M}$ sucrose for $5 \mathrm{~min}$ and stored in $30 \%$ sucrose at $4^{\circ} \mathrm{C}$. Paraffin wax sections were obtained for histological analysis. The hippocampus were excised from the fixed brain and dehydrated in ascending grades of alcohol $(50 \%, 70 \%, 90 \%$, and $100 \%)$. The tissues were then cleared in xylene twice for $15 \mathrm{~min}$ each. Infiltration was done with paraffin wax in Leica hot air oven at $56^{\circ} \mathrm{C}$ with tissues eventually embedded in paraffin wax at similar orientations. Tissue sections were obtained serially using a rotary microtome (Leica RM2245) and then mounted on glass slides. Sections were taken at 30 $\mu \mathrm{m}$ for haematoxylin and eosin (H\&E) staining process using the method of Pearse (1975) as modified by Fischer et al. (2008). The slides were analysed using Leica®DM5000B microscope and photographed with Leica EC3 digital camera.

\section{Quantitative Analysis}

After the H\&E staining process, quantitative assessment of the percentage number of surviving neurons was conducted. The assessment was based on selection of five sections from each rats viewed using light microscope under 400× (Leica®DM5000B microscope). The cells were counted stereologically for surviving neurons (healthy neurons with distinct nucleus) and the obtained data were statistically analysed (Wilcock et al. 2006; Kenawy et al. 2017).

\section{Biochemical Analysis}

The brain tissues were placed in $0.25 \mathrm{M}$ sucrose solution and homogenized. Tissue homogenate was collected in a $5 \mathrm{~mL}$ sample bottle and centrifuged at 3,000 rpm for 15 min using a centrifuge (Model 90-1; Jiangsu Jinyi Instrument Tech, Jiangsu, China). The supernatant was collected with Pasteur pipettes into sample bottles and placed in a freezer at $-4{ }^{\circ} \mathrm{C}$.

Superoxide Dismutase (SOD) Assay: SOD assay was done using spectrophotometric technique (Sun and Zigman 1978). The reaction mixture $(3 \mathrm{~mL})$ 
contained $2.95 \mathrm{~mL}$ carbonate buffer, $0.02 \mathrm{~mL}$ of homogenate and $0.03 \mathrm{~mL}$ of $2 \mathrm{mM}$ SOD substrate in 0.005 normal hydrochloric acid $(\mathrm{N} \mathrm{HCl})$, used to initiate the reaction. The reference cuvette contained $2.95 \mathrm{~mL}$ buffer, $0.03 \mathrm{~mL}$ of substrate and $0.02 \mathrm{~mL}$ of water. The absorbance was read at regular interval of 1-5 min at $480 \mathrm{~nm}$, with values expressed in $\mathrm{U} / \mathrm{mg}$ of protein.

Catalase (CAT) Assay: CAT activity was analysed using the protocols of Clairborne (1995), in a solution containing $50 \mathrm{mM}$ phosphate buffer, $19 \mathrm{mM}$ hydrogen peroxide and tissue homogenates. The reaction was ended by addition of dichromate/ acetic acid solution, and values expressed as $\mu$ mole of $\mathrm{H}_{2} \mathrm{O}_{2}$ consumed/mg protein/min.

Reduced Glutathione (GSH) Level: GSH was assayed using the protocols of Jollow et al. (1974) in a solution containing tissue homogenates, $4 \%$ sulphosalicylic acid, and subsequently 5,5'-dithiobis2-nitrobenzoic acid, with values expressed in $\mathrm{nmol} / \mathrm{mg}$ of protein.

Lipid Peroxidation (LPO) Level: LPO was quantified as malondialdehyde (MDA), using the protocols of Farombi et al. (2000). The reaction contained tissue homogenates, $5 \%(\mathrm{w} / \mathrm{v})$ butylated hydroxytoluene (BHT), 10\% tricyclic antidepressant and $0.75 \%$ in $0.1 \mathrm{~mol} / \mathrm{L}$ of $\mathrm{HCl}$. MDA was calculated using the following equation: R1/41.56_105 L/mol/cm, where $R$ is the extinction coefficient, Values expressed in $\mathrm{nmol} / \mathrm{mg}$ of protein or $\mathrm{U} / \mathrm{mg}$ protein.

Determination of Nitric Oxide (NO) Level: Nitric oxide measured as nitrite was determined according to the method of Moshage et al. (1995). Briefly, $2 \mathrm{~mL}$ of $10 \mathrm{mM}$ of sodium nitroprusside was prepared in $0.5 \mathrm{~mL}$ of phosphate buffer saline ( $\mathrm{pH} 7.4$ ). Next, 0.5 $\mathrm{mL}$ of sample extract was added and incubated at 25 ${ }^{\circ} \mathrm{C}$. After $150 \mathrm{~min}$ of incubation, $0.5 \mathrm{~mL}$ of Griess reagent $\quad(1 \% \quad$ sulphanilamide, $2 \%$ hydrogen tetraoxophosphate $(\mathrm{VI})$, and $0.1 \%$ naphthyl ethylene diamine dihydrochloride) was added to $0.5 \mathrm{~mL}$ of incubated solution. The reaction mixture was reincubated for $30 \mathrm{~min}$ at room temperature. The rate of absorbance was measured at $546 \mathrm{~nm}$, and the inhibition percentage was calculated as below. Values expressed in $\mu \mathrm{M} / \mathrm{g}$.

$\left[\left(\mathrm{A} 46_{\text {Control }}-\mathrm{A} 546_{\text {Sample }}\right) / \mathrm{A} 546_{\text {Control }}\right] \times 100$

Determination of Hydrogen Peroxide $\left(\mathrm{H}_{2} \mathrm{O}_{2}\right)$ Level: Hydrogen peroxide level was assayed as described by Aebi (1984). Briefly, $40 \mathrm{mM}$ of hydrogen peroxide solution was prepared in $50 \mathrm{mM}$ phosphate buffer ( $\mathrm{pH} \mathrm{7.4)} \mathrm{and} \mathrm{the} \mathrm{absorbance} \mathrm{was} \mathrm{measured} \mathrm{at} 230$ $\mathrm{nm}$. Then $1 \mathrm{~mL}$ of sample extract or standard was added with $2 \mathrm{~mL}$ of hydrogen peroxide solution. After $10 \mathrm{~min}$, the absorbance was measured against blank a solution. The blank solution was prepared with phosphate buffer without adding hydrogen peroxide. Then, the percentage of hydrogen peroxide was then calculated as below. Values are expressed in $\mathrm{mM} / \mathrm{g}$.

$\left[\left(\mathrm{A} 230_{\text {Control }}-\mathrm{A} 230_{\text {Sample }}\right) / \mathrm{A} 230_{\text {Control }}\right] \times 100$

Brain Monoamine Neurotransmitters Analysis: Monoamine neurotransmitters (dopamine, serotonin and norepinephrine) level was estimated as follows; wet tissue was weighed and homogenized in $5 \mathrm{~mL}$ $\mathrm{HCl}$ for $1 \mathrm{~min}$. The sample was then centrifuged for $10 \mathrm{~min}$ at $2000 \mathrm{rpm}$. An aliquot supernatant phase (1 $\mathrm{mL}$ ) was removed and added to centrifuge tube containing $2.5 \mathrm{~mL}$ heptane and $0.31 \mathrm{~mL} \mathrm{HCl}$ of $0.1 \mathrm{M}$. After $10 \mathrm{~min}$ of vigorous shaking, the tube was centrifuged under the same conditions as above in order to separate the two phases and the overlaying organic phase was discarded. The aqueous phase $(0.2 \mathrm{~mL})$ was then taken either for dopamine (DA), serotonin (5-HT) and norepinephrine (NE) assay. All steps were carried out at $0^{\circ} \mathrm{C}$ (Pagel et al. 2000).

For dopamine and norepinephrine analysis: $0.05 \mathrm{~mL}$ $0.4 \mathrm{M} \mathrm{HCl}$ and $0.1 \mathrm{~mL}$ of ethylene diamine tetra acetic acid /sodium acetate buffer $(\mathrm{pH}$ 6.9) were added to the $0.2 \mathrm{~mL}$ of aqueous phase, followed by $0.1 \mathrm{~mL}$ iodine solution $(0.1 \mathrm{M}$ in ethanol) for oxidation. The reaction was stopped after $2 \mathrm{~min}$ by addition of $0.1 \mathrm{~mL}$ di-sodium trioxosulphate (VI) solution. The $0.1 \mathrm{~mL}$ acetic acid was added after 1.5 min. The solution was then heated to $100{ }^{\circ} \mathrm{C}$ for 6 min when the sample again reached room temperature; excitation and emission spectra were read for dopamine and norepinephrine from the spectrofluorometer (model Jasco-FP-6500, Japan).

For serotonin analysis: $0.25 \mathrm{~mL}$ of $\mathrm{O}$-phthalaldehyde reagent was added to $0.2 \mathrm{~mL}$ aqueous extract. The fluorophore developed after heating to $100{ }^{\circ} \mathrm{C}$ for 10 min. After the samples reached equilibrium with the ambient temperature, readings were then taken in the spectrofluorometer (model Jasco-FP-6500, Japan).

\section{Statistical Analysis}

Statistical analysis was performed using Graph Prism ${ }^{\circledR}$ software (version 3.05 for Windows, GraphPad software, USA) by one-way analysis of variance with Tukey's multiple comparisons test. The data were reported as mean \pm standard error of Mean, while differences between means at $p<0.05$ were considered significant.

\section{RESULTS}

\section{Neurobehavioural Assessments}

Neurobehavioural tests (MWM and Y-maze) were carried out to estimate the duration of escape latency and the percentage of correct alternation, respectively. The results showed that there was a 
significant increase in the escape latency of $\mathrm{Pb}$ treated rats (group $B$ ) in comparison with the control (group $A)(p<0.05)$ (Fig. 1A) showing that Pb caused a decline in the long-term memory index. However, co-administration of SFN and Pb (group D) showed a significant decrease in escape latency period when compared with the $\mathrm{Pb}$-treated rats (group $B)(p<0.05)$ (Fig. 1a).

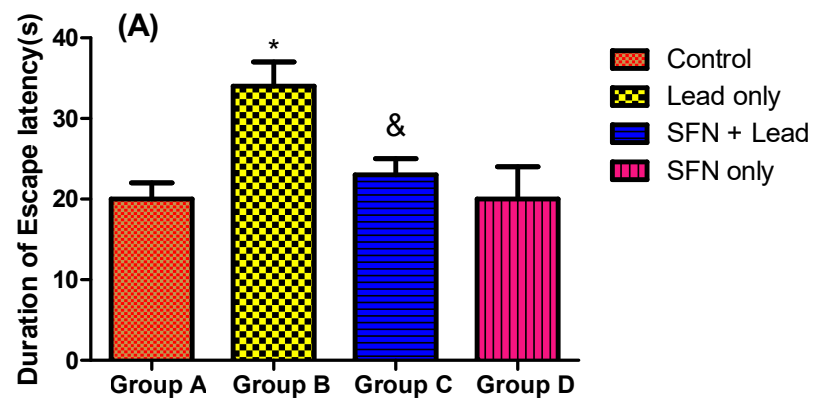

Animal grouping

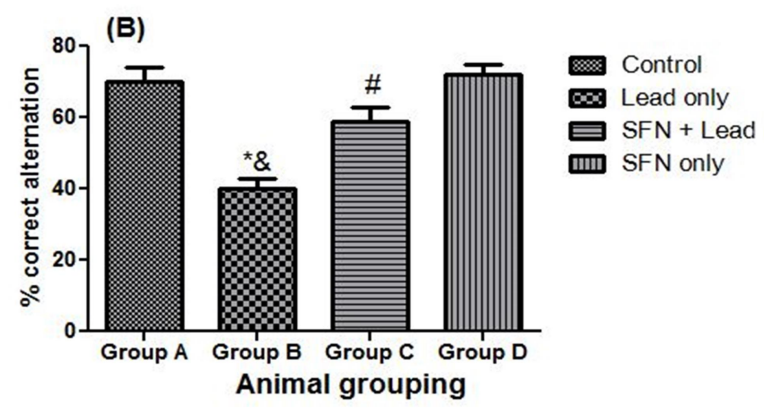

Fig. 1: Neurobehavioural stress tests in normal and treated rats. A: Morris water maze; $\mathrm{B}$ : Y-maze test. * $p<0.05$ compared to group $A ; \&$ : $p<0.05$ compared to group B. \# - p $<0.05$ compared to group A

Furthermore, the percentage of correct alternation observed in the $\mathrm{Y}$-maze test showed a significant decrease among $\mathrm{Pb}$ only rats (group $\mathrm{B}$ ) in comparison with the control group (group $A)(p<0.05)$ (Fig. 1b). However, the group treated with a combination of SFN and $\mathrm{Pb}$ (group $\mathrm{C}$ ) showed significant increase in correct alternation compared with $\mathrm{Pb}$ only rats (group $\mathrm{B})(\mathrm{p}<0.05)$ (Fig. $1 \mathrm{~b}$ ), while the SFN only rats (group D) showed similar correct alternation with the control rats (group A) (Fig. 1b).

\section{Sulphoraphane Response on Brain Monoamine Neurotransmitters (Dopamine, Serotonin and Norepinephrine)}

In this present study, the result showed that $\mathrm{Pb}$ only rats (group B) had significant decrease levels of serotonin and dopamine with concomitant increase in norepinephrine level when compared with the control rats (group A) $(p<0.05) \quad($ Fig. 2). However, combination of SFN and $\mathrm{Pb}$ (group $\mathrm{C}$ ) significantly increased the levels of dopamine and serotonin with corresponding decrease in the level of norepinephrine when compared to the $\mathrm{Pb}$ only rats (group B) $(p<0.05)$ (Fig. 2).

\section{Sulphoraphane Response on Brain Antioxidant Parameters (CAT, SOD, GSH) \\ The levels of CAT, SOD and GSH were measured to estimate antioxidant activity in the brain of rats treated with SFN and $\mathrm{Pb}$. The results showed a significant decrease in the levels of antioxidant enzymes among $\mathrm{Pb}$ only rats (group $\mathrm{B}$ ) when compared with the control rats (group $A)(p<0.05)$ (Fig. 3). However, the co-administration of SFN and $\mathrm{Pb}$ (group $\mathrm{C}$ ) showed a significant increase in the levels of CAT, SOD and GSH when compared to $\mathrm{Pb}$ only rats (group $B) \quad(p<0.05)$. Although, the co- administration of SFN and $\mathrm{Pb}$ (Group $\mathrm{C}$ ) showed a significant decrease in brain antioxidant enzyme levels when compared with control and SFN only rats (groups A and D) $(p<0.05)$ (Fig. 3)}

\section{Sulphoraphane Effects on Brain Oxidative Stress markers (MDA, $\mathrm{H}_{2} \mathrm{O}_{2}$ and $\mathrm{NO}$ )}

In the present study, there was a significant increase in the levels of MDA, $\mathrm{H}_{2} \mathrm{O}_{2}$ and $\mathrm{NO}$ in $\mathrm{Pb}$ only treated rats (group $\mathrm{B}$ ) when compared with the control rats (group $A)(p<0.05)$ (fig. 4). However, there was a significant decrease in the levels of MDA, $\mathrm{H}_{2} \mathrm{O}_{2}$ and $\mathrm{NO}$ among the rats that was treated with SFN and $\mathrm{Pb}$ (group $\mathrm{C}$ ) compared to $\mathrm{Pb}$ only rats (group $\mathrm{B}$ )
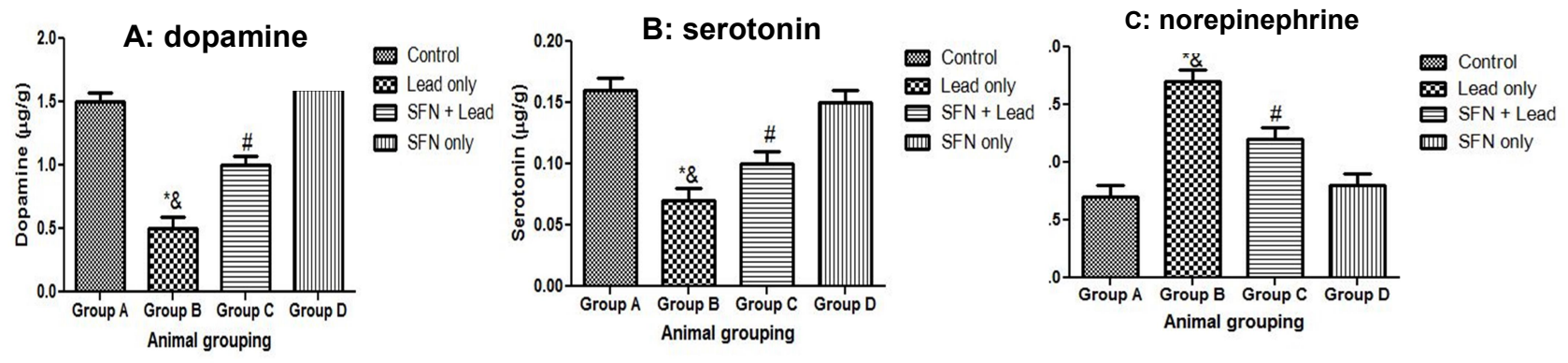

Fig. 2: Brain neurotransmitters (dopamine, serotonin and norepinephrine) in normal and treated rats. * $-p<$ 0.05 compared to group $A ; \&-p<0.05$ compared to group $C$; \# - p < 0.05 compared to groups A 
$(p<0.05)$ (Fig. 4). Although, there was a significant increase in brain oxidative stress markers among the rats that were treated with SFN and $\mathrm{Pb}$ (group $\mathrm{C}$ ) compared with control and SFN only rats (groups $A$ and D) $(p<0.05)$ (Fig. 4). the hippocampal neurons showed a significant decrease in the percentage surviving neurons among $\mathrm{Pb}$ only treated rats (group $\mathrm{B}$ ) in comparison with the control (group A) $(p<0.05)$ (Fig.6). However, coadministration of SFN and $\mathrm{Pb}$ (group $\mathrm{D}$ ) revealed a
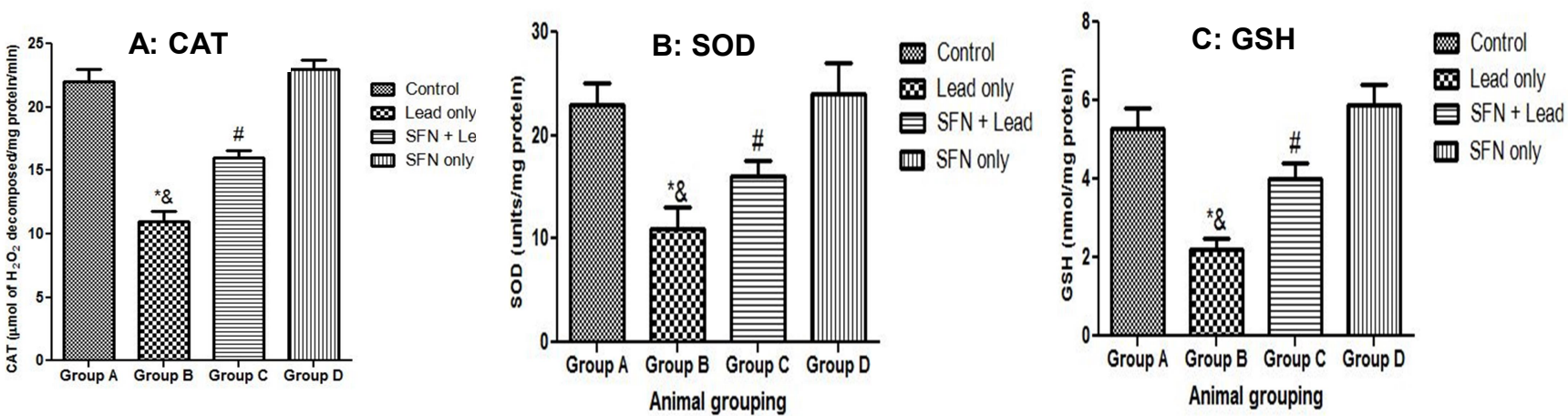

Fig. 3: Brain antioxidant parameters in normal and treated rats. *: $p<0.05$ compared to group $A ; \&$ : $p<0.05$ compared to group C; \#: $p<0.05$ as compared to groups A.

\section{Histological Observation of the CA3 Region}

The representative photomicrograph of the $\mathrm{Pb}$ only rats (group B) showed protruding eosinophilic cytoplasm, pyknotic nuclei, decrease and shrinkage pyramidal cells (degenerated neurons) in the pyramidal layer, dilated bold vessels and dispersed vacuolization compared with the control rats (group A) (Fig. 5b). However, co-administration of SFN and $\mathrm{Pb}$ rats (group $\mathrm{C}$ ) showed nearly normal morphological features of the hippocampus compared with $\mathrm{Pb}$ only treated rats (Fig. 5c). Additionally, the SFN only rats (group D) showed similar histological features with control rats (group A) displaying intact neurons with prominent nucleoli within the pyramidal layer of visible pyramidal cells (Fig. 5d).

Furthermore, quantitative assessments conducted on significant increase in the percentage surviving neurons compared with the $\mathrm{Pb}$ only treated rats (group B) $(p<0.05)$ (Fig. 6). In addition, the coadministration of SFN and $\mathrm{Pb}$ (group $\mathrm{C}$ ) showed a significant decrease in the percentage surviving neurons when compared with control and SFN only rats (groups A and D) ( $p<0.05)$ (Fig. 6).

\section{DISCUSSION}

The emergence of several debilitating disorders and diseases around the globe has drastically affected socio-economic growth. One of such disorders is AD, widely known for its negative influence on memory and cognitive skills, as well as on the ability to perform normal daily activities (Bakulski et al. 2012).
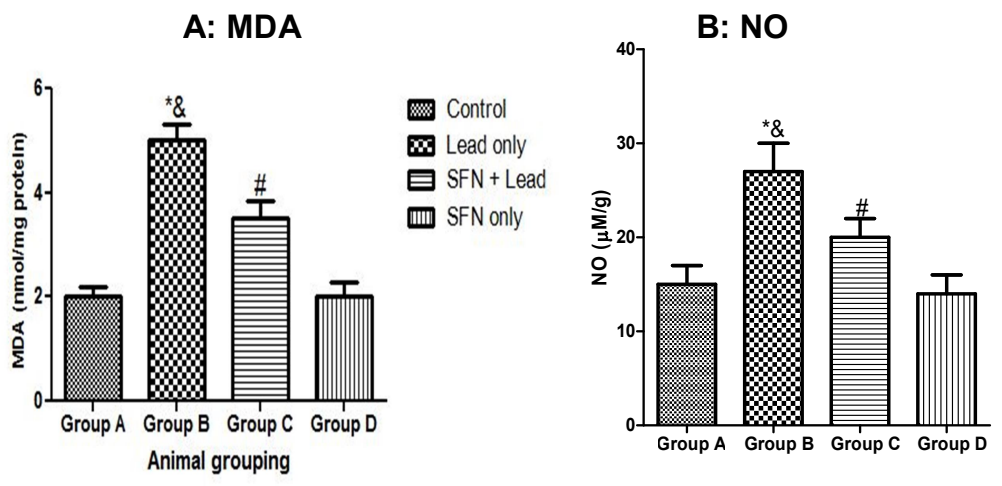

C: $\mathrm{H}_{2} \mathrm{O}_{2}$
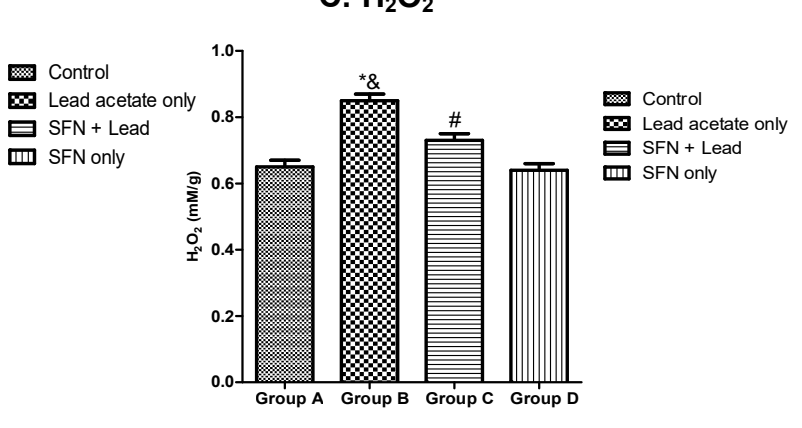

Fig. 4: Brain oxidative stress markers in normal and treated rats. ${ }^{*}-p<0.05$ compared to group $A ; \&-p<0.05$ as compared to group $\mathrm{C}$; \# - $\mathrm{p}<0.05$ as compared to groups $\mathrm{A}$ 
Several researchers in an attempt to source for potential ways to cure or manage the disease have made investigations into the root causes thereby linking heavy metal neurotoxicity to be one of the factors implicated in the pathogenesis of $A D$ (Bakulski et al. 2012; Mason et al. 2013). Studies have indicated the occurrence of its adverse effects on the CNS by affecting cognition, learning and memory after chronic $\mathrm{Pb}$ exposure (Bellinger 2011). In this study, the Morris water and $\mathrm{Y}$-maze tests are designed specifically to evaluate long and short term memory by measuring the duration of escape latency and percentage of correct alternation, respecttively in rat model neural damage (Omotoso et al. 2018). The present result observed a drastic increase in the escape latency and concomitant decrease in percentage correct alternation in $\mathrm{Pb}$-treated rats. This implies that $\mathrm{Pb}$ has a negative effect on cognitive capacity thereby inducing memory impairment as seen in $A D$ patients. The memory alterations observed in this study is in accordance with previous studies that implicated memory and cognitive

deficit to be induced by oxidative imbalance in which changes in antioxidant and pro-oxidants markers resulted in oxidative stress thereby damaging specific regions of the CNS (hippocampus) responsible for learning and memory (Riedel and Micheau 2001; Neves et al. 2015; Omotoso et al. 2020). However, the co-administration of SFN and $\mathrm{Pb}$ showed a reduced period of escape latency and higher correct alternation suggesting the ameliorative potential of $\mathrm{SFN}$ in reversing the memory impairment against $\mathrm{Pb}$ exposure. Previous studies have shown that SFN administration reduces memory deficits in mouse models due to its anti-oxidative and anti-inflammatory ability to scavenge free radicals and stop inflammatory responses in cells, thus improving learning and working memory (Hou et al. 2018; Lee et al. 2018). Similarly, SFN administration was reported to prevents or decelerates the process of normal brain aging and averts the occurrence of memory problems (Sunkaria et al. 2018), reduces the amount of amyloid beta $(A \beta)$ and phosphorylated tau proteins as well as their aggregation (the typical

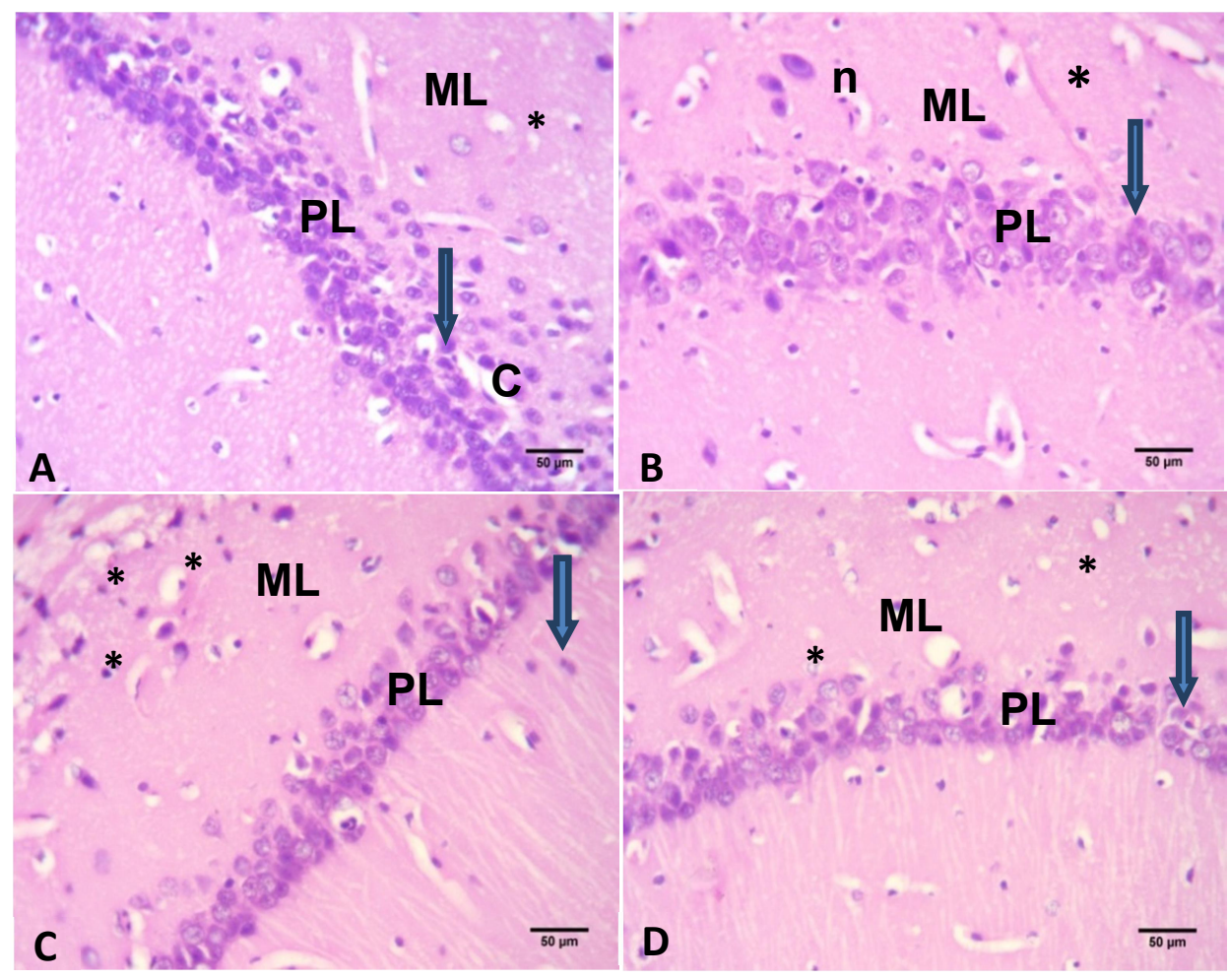

Fig. 5: A: Control showing normal hippocampus morphology of the Cornu Ammonis CA3) region with compact layers of prominent pyramidal cells and vesicular nuclei, neuronal process of the pyramidal layer $(\mathrm{PL})$; $\mathrm{B}$ : Lead acetate only group showing loss and shrinkage in size of pyramidal cells (arrow), marked enlargement of neurons $(n)$ and of glial cells $\left({ }^{*}\right)$ within the marginal layer $(\mathrm{ML})$. C. SFN and lead acetate group showing preserved glial cells $\left(^{*}\right)$ in the molecular layer $(\mathrm{ML})$ with few restored within the molecular layer (ML) and pyramidal cells (arrow) among neuronal process similar to the control. C - vacuolation; H\&E, $\times 200$

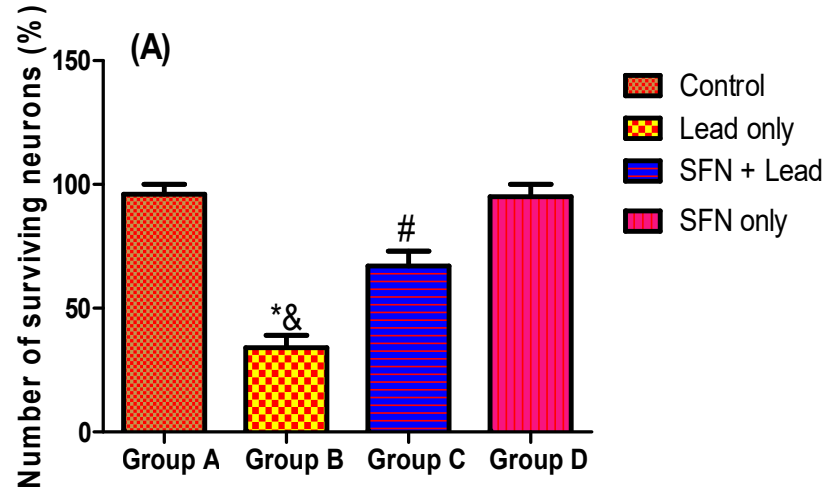

Animal grouping

Fig. 6: Quantitative assessment of the number of surviving neurons in hippocampal sections * $-p<0.05$ compared to group A; \& - p < 0.05 compared to group C; \# - p $<0.05$ as compared to groups $\mathrm{A}$ 
hallmarks of AD) (Hou et al. 2018; Lee et al. 2018). The impairment of neurotransmission and deregulation of cell signalling are key aspects of $\mathrm{Pb}$ neurotoxicity (Sharma et al. 2015). The results showed a drastic depletion in dopamine and serotonin levels in the brain with corresponding increase in the level of norepinephrine after chronic $\mathrm{Pb}$-exposure compared to the control, thereby affecting neurotransmitters storage within the brain. However, the combination of SFN and $\mathrm{Pb}$ significantly increased the levels of dopamine and serotonin with corresponding decrease in norepinephrine when compared to $\mathrm{Pb}$ only group. This observation revealed a boost in neurotransmitter levels initiated by SFN administration in the treatment of $A D$. Neurotransmitters are important for proper brain functioning because they are necessary for the transport and balance of signals between nerve cells in the brain (Sharma et al. 2015).

The defence against reactive oxygen species (ROS) and free radicals are important in proper brain function (Omotoso et al. 2018). Pb exposure is capable of causing neurotoxicity directly through oxidative stress or indirectly through lipid peroxidation resulting in the generation of ROS and direct depletion of antioxidant reserves (Khan et al. 2000; Melo et al. 2011; Tarozzi et al. 2013). In this present study, there was significant decrease in antioxidant reserves (CAT, SOD, GSH) and corresponding elevation in levels of oxidative markers (MDA, NO and $\mathrm{H}_{2} \mathrm{O}_{2}$ ) among the group treated with $\mathrm{Pb}$ only when compared to the control. This signifies that $\mathrm{Pb}$ has a deleterious effect on antioxidant enzyme levels and oxidative stress markers thereby increasing the levels of free radicals within the brain. However, the group treated with SFN and $\mathrm{Pb}$ combination showed significant decrease in the antioxidant enzymes levels (CAT, SOD, GSH) with concomitant decrease in oxidative stress parameters (MDA, $\mathrm{NO}$ and $\mathrm{H}_{2} \mathrm{O}_{2}$ ) compared to the $\mathrm{Pb}$ only group. This implies that SFN administration was capable of boosting antioxidant enzyme levels by mopping up the free radicals that induces oxidative stress. Previous studies revealed that SFN has very strong antioxidant and anti-inflammatory properties which allow for a significant reduction in cytotoxicity in the CNS (Shapiro et al. 2006) thereby scavenging the excess ROS within the brain tissue. SFN increases the release of $\mathrm{GSH}$ by up to 2.4 fold in cultured astrocytes (Steele et al. 2013) and has been shown to reduce oxidative stress in multiple disease states in cultured cells and animal models (Dauer and Przedborski 2003; Huo et al. 2018).

Although the molecular mechanisms involved in the pathogenesis of acute and chronic neurodegenerative diseases remain elusive, oxidative stress, misfolding, aggregation, accumulation of proteins, disturbed calcium ion homeostasis, excitotoxicity, inflammation, and apoptosis have been identified as possible causative agents of neurodegeneration (Dauer and Przedborski; 2003; Mandel et al., 2003). The brain is particularly susceptible to oxidative stress due to its high level of oxygen consumption, high oxidizable polyunsaturated fatty acid content, and low antioxidant defence capacities especially in old and aging brains (Halliwell 1992; Hamilton et al. 2001; Arouma 2002).

Chronic $\mathrm{Pb}$ exposure is capable of inducing damage in the prefrontal cortex of the cerebrum, hippocampus, and cerebellum which then result in various neurological disorders, including brain damage, mental retardation, behavioural problems, nerve damage, Alzheimer's and Parkinson's diseases, and schizophrenia (Sanders et al., 2009). The present study affirmed that $\mathrm{Pb}$ causes alteration in the hippocampal histomorphology characterized by disorganized neurons, eosinophilic stained cytoplasm, nuclei swelling and neuronal shrinking similar to the pathological hallmark of AD. These observable features were reported to be mediated by amyloid beta (1-42) accumulation within the hippocampus thereby inducing memory impairments associated with neuronal injury (Mason et al. 2014; El-Boshy et al. 2015; Zhang et al. 2016). Additionally, neurotoxicants such as $\mathrm{Pb}$, aluminium, cuprizone, nickel, manganese) were reported to compromise structural composition of neurons through oxidative stress induced cellular damage by elevating neurotoxins levels capable of destroying the nuclear component of the cell (Omotoso et al. 2018). $\mathrm{Pb}$ is also known to restrict the release of neurotransmitters, thus affecting their availability in the brain and disrupting the function of GABAergic, dopaminergic and cholinergic systems (Hamilton et al. 2001; Sharma et al. 2015). Pb exposure is a major public health concern with evidence showing its adverse effects on the CNS as well as on motor and cognitive skills, and exposure during early life stages can cause neurodegeneration such as in $A D$ in later life (Mason et al. 2014; Sharma et al. 2015). The photomicrograph of the SFN-treated group revealed mild neuronal degeneration with lesser number of eosinophilic stained neurons and increased number of healthy neurons with prominent nuclei thereby showing the attenuating potency of SFN on neurodegeneration and also preserving cognitive functions. The altered histological presentation observed in this study is in accordance with previous researchers (El-Boshy et al. 2015; Zhang et al. 2016) suggesting that neurotoxicant causes injury due to excess formation of free radicals in the brain. The administration of SFN further reinforced its capability to reverse the symptoms of Alzheimer's-type neurodegeneration brought about by chronic $\mathrm{Pb}-$ exposure. SFN is a potent activator of the Nrf2-ARE genetic pathway. Up-regulation of the Nrf2-ARE pathway increases the availability of multiple antioxidants in the brain, thus increasing its defence against oxidative stress and it effects (Klomparens 
and Ding 2019). Studies have suggested that SFN supplementation could suppress many debilitating CNS diseases including AD, Parkinson's disease, epilepsy and stroke (Wang et al. 2016; Klomparens and Ding 2019).

\section{Conclusion}

It can thus be concluded that chronic $\mathrm{Pb}$ exposure is a major environmental neurotoxicant capable of causing memory impairments and hippocampal neurodegeneration in Alzheimer type animal model and SFN supplementation play a major role in preventing or mitigating the deleterious neurotoxicity of $\mathrm{Pb}$ exposure thereby allowing the proper cognitive function and normal homeostasis.

\section{Conflict of Interest}

None declared

\section{Acknowledgements}

The authors are grateful to $\mathrm{Dr}$ Omamuyovwi ljomone. Department of Human Anatomy, Federal University of Technology Akure, Nigeria for the photomicrograph capturing; Mr. Daniel Dan of Anatomical Pathology Laboratory, Department of Morbid and Anatomical Pathology for the slides preparation, and Mrs Abosede Ogunlade, Department of Haematology and Blood Transfusion, College of Medicine, University of Lagos, Nigeria for the biochemical Analysis.

\section{REFERENCES}

Aebi, H.E. (1984) Methods of Enzymatic Analysis, vol. 105. Berlin: Verlag Chemicals. Pp. 121-126.

Agency for Toxic Substances and Disease Registry, ATSDR (2006) Toxicological Profile for Lead. Atlanta: US Department of Health and Human Services, Public Health Service. [Accessed 22 January, 2009]. Available at: http:/www.atsdr.cdc.gov.

Anderson, A.C., Pueschel, S.M. and Linakis, J.G. (1996) Pathophysiology of lead poisoning. In: Pueschel, S.M., Linakis, J.G. and Anderson, A.C. (eds). Lead Poisoning in Children. Baltimore, MD: P.H. Brookes. Pp.75-96.

Arouma, O.I. (2002) Neuroprotection by dietary antioxidants: new age of research. Nahrung. 46(6): 381-382.

Bakulski, K.M., Rozek, L.S., Dolinoy, D.C., Paulson, H.L. and Hu, H. (2012) Alzheimer's disease and environmental exposure to lead: the epidemiologic evidence and potential role of epigenetics. Current Alzheimer Research. 9(5):563-573.

Bellinger, D.C. (2011) The protean toxicities of lead: new chapters in a familiar story. International Journal of Environmental Research in Public Health. 8:2593628.
Bertram, L. (2009) Alzheimer's disease genetics current status and future perspectives. International Review of Neurobiology. 84:167-184.

Caban-Holt, A., Mattingly, M., Cooper, G. and Schmitt, F.A. (2005) Neurodegenerative memory disorders: a potential role of environmental toxins. Neurologic Clinics. 23(2):485-521.

Clairborne, A. (1995) Catalase activity. In: Greewald, A.R. (ed). Handbook of Methods for Oxygen Radical Research. Florida: CRC. Pp. 237-242.

Dauer, W. and Przedborski, S. (2003) Parkinson's disease: mechanisms and models. Neuron. 39(6): 889-909.

El-Boshy, M.E., Risha, E.F. and Abdelhamid, F.M. (2015) Protective effects of selenium against cadmium induced hematological disturbances, immunosuppressive, oxidative stress and hepatorenal damage in rats. Journal of Trace Elements in Medical Biology. 29:104-110.

Farombi, E.O. (2000) Chemoprevention of 2acetylaminofluoreneinduced hepatotoxicity and lipid peroxidation in rats by kolaviron - a Garcinia kola seed extract. Food and Chemical Toxicology. 38:535541.

Fischer, A.H., Jacobson, K.A., Rose, J. and Zeller, R. (2008) Hematoxylin and eosin staining of tissue and cell sections. Cold Spring Harbor Protocol. doi:10.1101/pdb.prot4986.

Frisardi, V., Solfrizzi, V., Capurso, C., Kehoe, P.G. Imbimbo, B.P., Santamato, A., et al. (2010) Aluminum in the diet and Alzheimer's disease: from current epidemiology to possible disease-modifying treatment. Journal of Alzheimer's Disease. 20:17-30. Halliwell, B. (1992) Reactive oxygen species and the central nervous system. Journal of Neurochemistry. 59(5):1609-1623.

Hamilton, M.L., van Remmen, H. and Drake, J.A (2001) Does oxidative damage to DNA increase with age? Proceedings of the National Academy of Sciences of the United States of America. 98(18): 10469-10474.

Han, D.Y., Hoelzle, J., Dennis, B.C. and Hoffmann, M. (2011) A brief review of cognitive assessment in neurotoxicology. Neurologic Clinics. 29(3):581-590.

Hardy, J. (1997) Amyloid, the presenilins and Alzheimer's disease. Trends in Neuroscience; 20:154-159.

Hou, T.T., Yang, H.Y., Wang, W., Wu, Q.Q., Tian, Y.R. and Jia, J.P. (2018) Sulphoraphane inhibits the generation of amyloid $\beta$ oligomer and promotesspatial learning and memory in Alzheimer's disease (PS1V97L) transgenic mice. Journal of Alzheimer's Disease. 62:1803-1813.

Jollow, D.J. (1974) Bromobenzene induced liver necrosis: protective role of glutathione and evidence for 3,4bromobenzene oxide as the hepatotoxic metabolite. Pharmacology. 11:151-169.

Kenawy, S., Hegazy, R., Hassan, A., El-Shenawy, S., Gomaa, N., Zaki, H., et al. (2017) Involvement of insulin resistance in D-galactose-induced age-related 
dementia in rats: protective role of metformin and saxagliptin, PLoS One. 12(8)

Khan, D.A., Qayyum, S., Saleem, S. and Khan, F.A. (2000) Lead-induced oxidative stress adversely affects health of the occupational workers. Toxicology and Industrial Health. 24:611-618.

Kim, J., Lee, S., Choi, B.R., Yang, H., Hwang, Y. and Park, J.H. (2017) Sulphoraphane epigenetically enhances neuronal BDNF expression and TrkB signaling pathways. Molecular Nutrition and Food Research. 61:1600194.

Kim, S.M., Kim, H., Lee, J.S., Park, K.S., Jeon, G.S., Shon, J., et al. (2013) Intermittent hypoxia can aggravate motor neuronal loss and cognitive dysfunction in ALS mice. PLoS One. 8:81808.

Klomparens, E.A. and Ding, Y. (2019) The neuroprotective mechanisms and effects of sulphoraphane. Brain Circulations. 5:74-83.

Lee, S., Choi, B.R., Kim, J., LaFerla, F.M., Park, J.H. and Han, J.S. (2018) Sulphoraphane upregulates the heat shock protein co chaperone CHIP and clears amyloid $\beta$ and tau in a mouse model of Alzheimer's disease. Molecular Nutrition and Food Research. 62:e1800240.

Mandel, S., Grunblatt, E., Riederer, P., Gerlach, M., Levites, Y. and Youdim, M.B.H. (2003) Neuroprotective strategies in Parkinson's disease: an update on progress. CNS Drugs. 17(10):729-762.

Mason, L.H., Harp, J.P. and Han, D.Y. (2014) Lead neurotoxicity: neuropsychological effects of lead toxicity. BioMed Research International. 2014:840547. http://dx.doi.org/10.1155/2014/840547. Mason, L.H., Mathews, M.J. and Han, D.Y. (2013) Neuropsychiatric symptom assessments in toxic exposure. Psychiatric Clinics of North America. 36(2):201-208.

Melo, A., Monteiro, L., Lima, R.M., de Oliveira, D.M., de Cerqueira, M.D. and El-Bach'a, R.S. (2011) Oxidative stress in neurodegenerative diseases: mechanisms and therapeutic perspectives. Oxidative Medicine and Cellular Longevity. 2011:467180.

Monnet-Tschudi, F., Zurich, M.G., Boschat, C., Corbaz, A. and Honegger, P. (2006) Involvement of environmental mercury and lead in the etiology of neurodegenerative diseases. Reviews on Environmental Health. 21(2):105-117.

Moshage, H. (1995) Nitrite and nitrate determinations in plasma: a critical evaluation. Clinical Chemistry. 41:892-896.

Neves, B.H., Menezes, J., Souza, M.A. and MelloCarpes, P.B. (2015) Physical exercise prevents short and long-term deficits on aversive and recognition memory and attenuates brain oxidative damage in $\neg$ duced by maternal deprivation. Physiological Behaviour. 152:99-105.

Omotoso, G.O., Gbadamosi, I.T., Afolabi, T.T., Abdulwahab, A.B. and Akinlolu, A.A. (2018) Ameliorative effects of moringa on cuprizone-induced memory decline in rat model of multiple sclerosis. Anatomt and Cell Biology. 51:119-127.
Omotoso, G.O., Mutholib, N.Y., Abdulsalam, F.A. and Bature, A.I. (2020) Kolaviron protects against cognitive deficits and cortico-hippocampal perturbations associated with maternal deprivation in rats. Anatomy and Cell Biology; 53:95-106

Owoeye, O. and Ojora, K.A. (2015). Tomato pomace alleviated motor abnormality, oxidative impairments and neurotoxicity induced by lead in Male Rats. Afr.J. Biomedical Research; 18:201- 210.

Pagel, P., Blome, J. and Wolf, H.U. (2000) Highperformance liquid chromatographic separation and measurement of various biogenic compounds possibly involved in the pathomechanism of Parkinson's disease. Journal of Chromatographic in Biomedical Science. 746:297-304.

Pauletti, A., Terrone, G., Shekh Ahmad, T., Salamone, A., Ravizza, T. and Rizzi, M. (2017) Targeting oxidative stress improves disease outcomes in a rat model of acquired epilepsy. Brain. 140:1885-1899.

Pearse, A.G. (1975). The role of histochemistry in increasing objectivity in histopathology. Postgraduate Medical Journal; 51:708-710.

Riedel, G. and Micheau, J. (2001) Function of the hippocampus in memory formation: desperately seeking resolution. Progress in Neuropsychopharmacology in Biological Psychiatry. 25:835-853.

Sanders, T., Liu., Buchner, V. and Tchounwou, P.B. (2009) Neurotoxic effects and biomarkers of lead exposure: a review. Review in Environmental Health. 24(1):15-45.

Shapiro, T.A., Fahey, J.W., Dinkova Kostova, A.T., Holtzclaw, W.D., Stephenson, K.K. and Wade, K.L. (2006) Safety, tolerance, and metabolism of broccoli sprout glucosinolates and isothiocyanates: A clinical phase I study. Nutrition in Cancer. 55: 53-62.

Sharma, P., Chambial, S. and Shukla, K.K. (2015) Lead and Neurotoxicity. Indian Journal of Clinical Biochemistry. 30(1):1-2. doi 10.1007/s12291-0150480-6.

Shcherbatykh, I. and Carpenter, D.O. (2007) The role of metals in the aetiology of Alzheimer's disease. Journal of Alzheimers Diseases. 11:191-205.

Shiina, A., Kanahara, N., Sasaki, T., Oda, Y., Hashimoto, T. and Hasegawa, T. (2015) An open study of sulphoraphane rich broccoli sprout extract in patients with schizophrenia. Clinical Psychopharmacology Neuroscience. 13:62-67.

Steele, M.L., Fuller, S., Patel, M., Kersaitis, C., Ooi, L. and Münch, G. (2013) Effect of Nrf2 activators on release of glutathione, cysteinylglycine and homocysteine by human U373 astroglial cells. Redox Biology. 1:441-445.

Sun, M. and Zigman, S. (1978) An improved spectrophotometric assay for superoxide dismutase based on epinephrine autoxidation. Anal of Biochemistry. 90:81-89.

Sunkaria, A., Bhardwaj, S., Yadav, A., Halder, A. and Sandhir, R. (2018) Sulphoraphane attenuates 
postnatal proteasome inhibition and improves spatial learning in adult mice. Journal of Nutritional Biochemistry. 51:69-79.

Tarozzi, A., Angeloni, C., Malaguti, M., Morroni, F., Hrelia, S. and Hrelia, P. (2013) Sulphoraphane as a potential protective phytochemical against neurodegenerative diseases. Oxidative Medicine and Cellular Longevity. 2013:415078, http://dx.doi.org/10. 1155/2013/415078.

Trio, P.Z., Fujisaki, S., Tanigawa, S., Hisanaga, A., Sakao, K. and Hou, D.X. (2016) DNA microarray highlights Nrf2 mediated neuron protection targeted by wasabi derived isothiocyanates in IMR 32 cells. Gene Regulation and System Biology. 10:73-83.

Vorhees, C.V. and Williams, M.T. (2006) Morris water maze: procedures for assessing spatial and related forms of learning and memory. Nature Protocol. 1:848-858.
Wang, G., Fang, H., Zhen, Y., Xu, G., Tian, J. and Zhang, Y. (2016) Sulphoraphane prevents neuronal apoptosis and memory impairment in diabetic rats. Cell Physiology and Biochemistry. 39:901-907.

Wilcock, D.M., Gordon, M.N. and Morgan, M. (2006) Quantification of cerebral amyloid angiopathy and parenchymal amyloid plaques with Congo red histochemical stain. Nature Protocol: 1 (3)

Zhang, R., Wang, L. and Zhao, J. (2016) Effects of selenium and cadmium on ion-profiles in the brains of chickens. Biological Trace Element Research. 174(1):218-225.

Zhou, Q., Chen, B., Wang, X., Wu, L., Yang, Y. and Xiaolan-Cheng, X. (2016) Sulphoraphane protects against rotenone-induced neurotoxicity in vivo: Involvement of the mTOR, Nrf2, and autophagy pathways. Scientific Reports. 6:32206.

Cite as Ogunlade, B., Afolayan, O.O., Adelakun, S.A. (2020) Sulphoraphane supplementation ameliorates behavioural impairments and hippocampal neurodegeneration induced by lead exposure in adult Wistar rats. Nig. J. Neurosci. 11(2):88-98. http://doi.org/10.47081/njn2020.11.2/005

(C) Copyright Nigerian Journal of Neuroscience. All rights reserved. 